\title{
ESTUDO DA COMPETIÇÃO POR SÍTIO ATIVO NA ADSORÇÃO MULTICOMPONENTE DOS COMPOSTOS BTX EM COLUNA DE LEITO FIXO UTILIZANDO CARVÃO ATIVADO COMO ADSORVENTE
}

\author{
A. D. da LUZ ${ }^{1}$, C. da LUZ ${ }^{2}$, A. A. ULSON DE SOUZA ${ }^{3}$ e S. M. A. GUELLI ULSON DE \\ SOUZA $^{3}$ \\ ${ }^{1}$ Universidade Federal da Fronteira Sul, Departamento de Engenharia Ambiental \\ ${ }^{2}$ Fundação Universidade do Estado de Santa Catarina, Curso de Eng. de Alimentos \\ ${ }^{3}$ Universidade Federal de Santa Catarina, Departamento de Engenharia Química e Engenharia \\ de Alimentos \\ E-mails para contato: adriana.luz@uffs.edu.br, selene@enq.ufsc.br
}

\begin{abstract}
RESUMO - A remoção de compostos orgânicos voláteis como benzeno, tolueno e xilenos (BTX) do efluente da indústria petroquímica é de interesse considerável, devido o alto grau de toxicidade destes compostos. Investigações na remoção da maioria dos grupos de hidrocarbonetos por adsorção tem focado em compostos individuais; entretanto no efluente da indústria petroquímica existe uma mistura de compostos tóxicos a serem removidos. Assim, neste trabalho, foi realizado o estudo da adsorção dos compostos BTX em coluna de leito fixo a fim de investigar a competitividade por sítio ativo entre os contaminantes, utilizando-se como adsorvente o carvão ativado de casca de coco. Os resultados mostraram que dos três contaminantes estudados o o-xileno foi o mais competitivo pelo sítio ativo, sendo que depois de um certo tempo ele consegue expulsar os compostos mais fracamente adsorvidos no topo da coluna e adsorver nos sítios ativos livres.
\end{abstract}

Palavras-chave: Adsorção Multicomponente, Competitividade, BTX.

\section{INTRODUÇÃO}

A contaminação de recursos naturais, especificamente os hídricos, tem levado à maior conscientização da população para a necessidade da preservação do meio ambiente. É notório que o lançamento de efluentes não tratados ou que não seguem os limites impostos pela legislação ambiental, aumentou nas últimas décadas com impactos eutróficos severos sobre a fauna, flora e nos próprios seres humanos (Luz, 2013).

Diante disso nota-se que nas últimas décadas a preocupação e a conscientização, por parte dos governos e população do planeta, têm aumentado. Prova disso são os encontros de cúpulas governamentais e de movimentos sociais para discutir os problemas ambientais que afetam o planeta. Um destes encontros mais recente é a Rio +20 , que em um documento de acordo entre 
os governos participantes enfatiza a ideia do Desenvolvimento Sustentável, buscando consolidar o desenvolvimento econômico com a preservação ambiental. Mais especificamente sobre a preservação dos recursos hídricos, cita-se o item 124 do documento "The future we want": "Ressaltamos a necessidade de adotar medidas para reduzir significativamente a poluição da água e aumentar a qualidade da água, melhorar significativamente o tratamento de esgoto $e$ reduzir as perdas de água. Para alcançar isso, enfatizamos a necessidade de assistência $e$ cooperação internacionais” (Ministério da Saúde, 2000).

Grande parte da contaminação dos recursos hídricos ocorre através do descarte de resíduos industriais. $\mathrm{O}$ controle desses descartes se dá através das rígidas legislações ambientais nas quais as empresas devem se adequar. Para isso as indústrias buscam novas tecnologias e processos mais eficientes na remoção desses contaminantes, processos menos onerosos de menor custo de instalação e operação, unidades mais compactas que operem com maior flexibilidade e com bom desempenho na remoção dos compostos tóxicos (Guelli U. de Souza et al., 2008).

Os compostos BTX, benzeno, tolueno e xilenos, presentes nos efluentes das indústrias do petróleo são hidrocarbonetos que apresentam elevado potencial de contaminação (Murata et al., 1999; Hernández et al., 2005). A USEPA (United States Environmental Protection Agency) classificou estes compostos como contaminantes de prioridade química (Dean, 1985). Eles são poderosos depressores do sistema nervoso central, apresentando toxicidade crônica e potencial mutagênico, mesmo em pequenas concentrações. O benzeno é o mais tóxico dentre os compostos BTX, devido à sua confirmada ação carcinogênica, podendo causar leucemia e tumores em múltiplos órgãos. Uma exposição aguda por inalação ou ingestão pode causar até mesmo a morte de uma pessoa (Dean, 1985).

Investigações sobre a remoção da maior parte dos grupos de hidrocarbonetos, pelo processo de adsorção tem se concentrado no estudo de componentes individuais (Wibowo et al., 2007; Hernández et al., 2005; Hu et al., 2001; Lin, and Huang, 1999). Entretanto, no efluente industrial, tem-se uma mistura de compostos tóxicos a serem removidos. Medições experimentais de equilíbrios de adsorção multicomponentes são complicadas para se analisar, especialmente quando o número de componentes ultrapassa dois (Kouyoumdjiev, 1992), além do que é pouco encontrado na literatura (Khan et al., 2000).

Um projeto otimizado para adsorção multicomponente deve levar em conta as interações entre a mistura dos compostos e vários fatores de natureza física e química do adsorvente e do adsorbato (Sulaymon e Ahmed, 2008). O estudo destes efeitos é de grande importância para obtenção das condições operacionais em uma coluna de adsorção operando com remoção multicomponente em um processo continuo.

Estudos realizados para determinar as características do processo de adsorção para remoção de compostos orgânicos voláteis multicomponente mostrou um ótimo desempenho quando utilizado carvões ativados como adsorvente (Luz et al., 2013). Segundo Wibowo et al. (2007), a adsorção com carvão ativado é uma tecnologia comprovada e confiável para a remoção de 
pequenas quantidades de compostos orgânicos solúveis em águas e efluentes na indústria sendo possível regenerá-lo e aproveitá-lo diversas vezes no processo.

Assim, este trabalho teve como objetivo estudar a adsorção multicomponente dos compostos BTX utilizando-se como adsorvente carvão vegetal de casca de coco ativado termicamente. Os ensaios da adsorção multicomponentes em coluna de leito fixo foram realizados com o objetivo de verificar a competitividade entre os contaminantes pelo sítio ativo do adsorvente. Foram estudadas as concentrações de $50,50,50 \mathrm{mg} / \mathrm{L}$ de cada contaminante na mistura, além de um estudo competitivo variando as concentrações dos contaminantes.

\section{MATERIAIS E MÉTODOS}

\subsection{Materiais}

O adsorvente utilizado foi o carvão vegetal produzido a partir de casca de coco e ativado termicamente com vapor e gás carbônico à temperatura de $800{ }^{\circ} \mathrm{C}$ a $1000^{\circ} \mathrm{C}$. Os solventes utilizados foram: água destilada para o preparo das soluções dos compostos BTX; Benzeno (marca Fluka) padrão HPLC, Tolueno (marca VETEC) padrão UV/HPLC - Espectroscópico e oXileno (marca Aldrich) padrão HPLC 98\%. Para uso no Cromatógrafo Líquido de Alta Eficiência (HPLC) foram utilizados água MiliQ e metanol série Gold da Carlo Erba padrão HPLC.

\subsection{Métodos}

Procedimento Experimental: Antes dos ensaios laboratoriais, as amostras passaram por tratamento prévio que consistiu no ajuste da granulometria do carvão ativado (18/20 MESH), aproximadamente $0.85 \mathrm{~mm}$, lavagem com água destilada e após secagem a $110^{\circ} \mathrm{C}$ por três horas. Para determinar a concentração dos compostos BTX foi utilizado um Cromatógrafo de fase líquida de alta eficiência, um HPLC (CG) conectado a um detector UV/visível (Modelo CG 437B) e uma coluna Nucleosil C18 fase reversa de $250 \mathrm{~mm}$, diâmetro interno de $4.6 \mathrm{~mm}$. Como fase móvel, para uso no HPLC, utilizou-se metanol e água MiliQ (80:20) a uma vazão de $0.8 \mathrm{~mL} / \mathrm{min}$. Os compostos BTX foram identificados em um comprimento de onda de $254 \mathrm{~nm}$. Todos os experimentos foram feitos em triplicada e o erro médio adotado foi menor que $5 \%$.

Caracterização do adsorvente: A caracterização do adsorvente foi realizada a partir dos seguintes ensaios: tamanho de partícula, dureza, testes de umidade, material volátil, cinzas e carbono fixo. Os testes BET (Brunauer, Emmett, and Teller) e BJH (Barrett, Joyner, and Halenda) foram feitos com o objetivo de conhecer a área superficial, volume de poros, distribuição do tamanho de poros e irregularidade da partícula de adsorvente utilizado. A análise de Microscopia Eletrônica de Varredura (MEV) foi realizada com a finalidade de se obter as micrografias da estrutura física do adsorvente. 


\section{9 a 22 de outubro de 2014 \\ Florianópolis/SC}

Cinética de adsorção em coluna de leito fixo: As cinéticas de adsorção mono e multicomponentes foram realizadas em processo contínuo, usando-se uma coluna de leito fixo empacotada com carvão ativado. A solução de alimentação dos compostos BTX mono e multicomponentes foram preparadas em frascos de vidro com capacidade de $4 \mathrm{~L}$ e a $23 \pm 1^{\circ} \mathrm{C}$. Para manter a solução homogênea e solúvel, utilizou-se um agitador magnético. Esta metodologia de agitação permitiu uma concentração reprodutível, que normalmente se manteve dentro de 2$3 \%$ do seu valor médio ao longo dos experimentos de adsorção, medido no ponto de entrada da coluna, antes do leito de carvão ativado.

Uma bomba peristáltica modelo GILSON foi empregada para transferir a solução de alimentação para a coluna com fluxo ascendente. A coluna de vidro consistiu de $7.0 \mathrm{~cm}$ de comprimento e $1.2 \mathrm{~cm}$ de diâmetro interno. Antes do leito de carvão ativado, um ponto de amostragem permitiu a retirada de amostras líquidas por utilização de seringas de vidro a fim de monitorar a concentração do contaminante na entrada do leito. Após o ponto de entrada da coluna, uma placa porosa foi posta a fim de suspender o leito de carvão ativado. $\mathrm{O}$ carvão ativado foi empacotado na coluna entre a placa porosa e uma zona de bolas de vidro que foram utilizadas para apoiar o carvão ativado no leito.

O fluxo de solução para a realização dos experimentos foi realizado da base da coluna para cima direcionando a solução de alimentação na vazão desejada. Para minimizar os efeitos de dispersão axial, a relação entre o comprimento do leito e o diâmetro de partícula, (L/dp), foi superior a 50 .

A concentração de alimentação tomada como referência para os experimentos cinéticos foi $50 \mathrm{mg} / \mathrm{L}$, que foi a concentração escolhida para as análises multicomponentes, considerando que a soma dos três contaminantes não ultrapassem ao limite de solubilidade do o-xileno (175 mg/L). As concentrações de compostos BTX, na entrada e na saída da coluna foram monitoradas com o tempo coletando-se amostras líquidas, que foram analisadas imediatamente, usando a cromatografia líquida de alta eficiência (HPLC).

\section{RESULTADOS E DISCUSSÕES}

\subsection{Caracterização do Carvão Ativado}

Através das análises físicas e químicas, verificou-se que o carvão ativado utilizado na adsorção dos compostos BTX apresentou baixo teor de umidade (0.03\% Base Seca) e quantidade de cinzas (1.4\% Base Seca) e alta quantidade de carbono fixo (94.99\% Base Seca).

Os resultados da caracterização textural do adsorvente apresentaram uma área superficial de $724 \mathrm{~m}^{2} / \mathrm{g}$. Para a extensão da microporosidade, os valores encontrados foram: volume de poro $=0,39 \mathrm{~cm}^{3} / \mathrm{g}$; diâmetro médio dos poros $=21.35 \AA$; ; volume do microporo $=0.31 \mathrm{~cm}^{3} / \mathrm{g}$; área do microporo $=614 \mathrm{~m}^{2} / \mathrm{g}$ e o tamanho do poro ficou distribuído entre o valor mínimo de $18 \AA \hat{\mathrm{e}} \mathrm{o}$ valor máximo de $400 \AA$. 
A Figura 1 apresenta o resultado da Microscopia Eletrônica de Varredura (MEV) do adsorvente utilizado. As ampliações realizadas foram de 500 e 1000 vezes o tamanho da partícula. Através desses resultados é possível verificar que o carvão ativado em estudo apresenta uma grande área superficial e um vasto volume de poros, o que caracteriza o carvão ativado de casca de coco como um ótimo adsorvente para a adsorção dos compostos BTX.

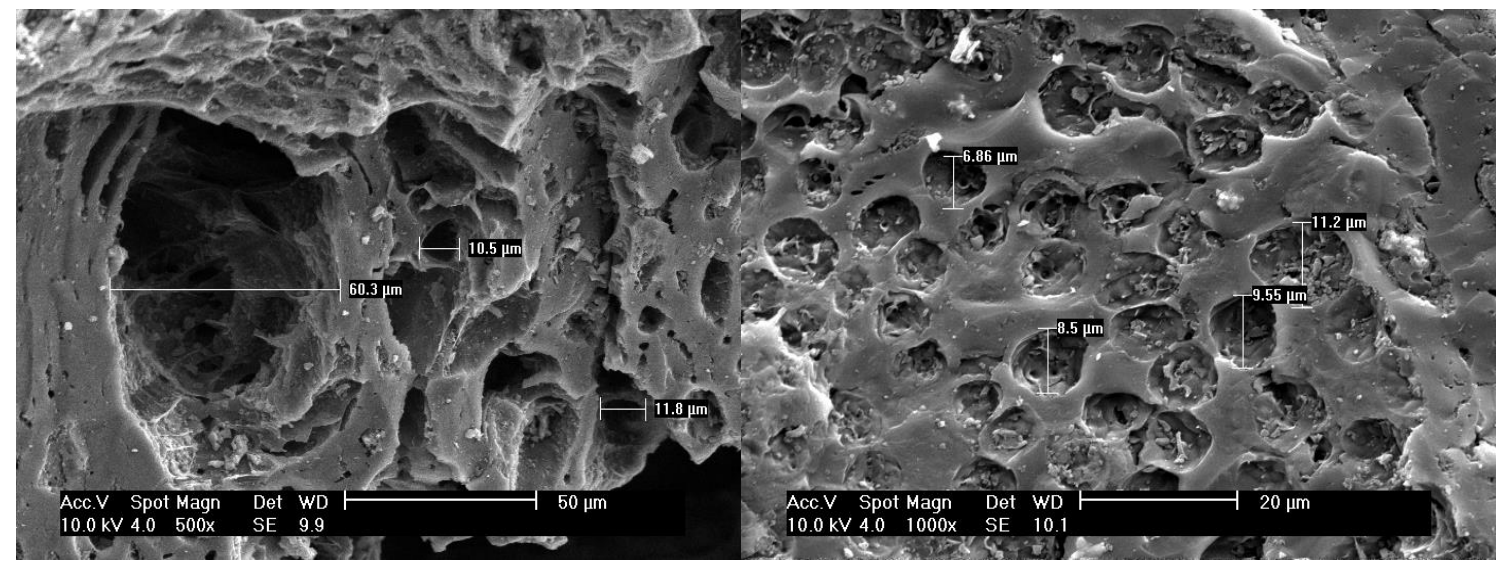

Figura 1 - Micrografias do carvão ativado vegetal de casca de coco.

\subsection{Adsorção Multicomponente}

Na Figura 2 são apresentados os resultados experimentais (a) - (d) das curvas de ruptura dos compostos BTX para algumas combinações ternárias dos contaminantes. Analisando a Figura 2 (a), que apresenta os resultados obtidos para a mistura tricomponente nas concentrações iniciais de $30 \mathrm{mg} / \mathrm{L}$ de benzeno, $30 \mathrm{mg} / \mathrm{L}$ de tolueno e $50 \mathrm{mg} / \mathrm{L}$ de o-xileno, observa-se que, por mais que a concentração do o-xileno seja a maior $(50 \mathrm{mg} / \mathrm{L})$ comparada ao benzeno $(30 \mathrm{mg} / \mathrm{L})$ e ao tolueno (30 mg/L), o o-xileno é o contaminante que é mais adsorvido pelo adsorvente. Segundo Daifullah e Girgis (2003), a adsorção dos compostos BTX é favorecida com a diminuição da solubilidade (B, $1790 \mathrm{mg} / \mathrm{L}>\mathrm{T}, 530 \mathrm{mg} / \mathrm{L}>\mathrm{o}-\mathrm{X}, 175 \mathrm{mg} / \mathrm{L})$ e o aumento do massa molar $(\mathrm{B}, 78 \mathrm{~g} / \mathrm{mol}<\mathrm{T}$, $92 \mathrm{~g} / \mathrm{mol}<\mathrm{o}-\mathrm{X}, 106 \mathrm{~g} / \mathrm{mol}$ ) dos compostos. Assim verifica-se que após $11 \mathrm{~h}$ de adsorção, a coluna não se encontra saturada com o o-xileno (70\% saturada), sendo que para o benzeno a coluna saturou em $5 \mathrm{~h}$ e para o tolueno em $5.5 \mathrm{~h}$.

Sabe-se que no início da adsorção tem-se uma grande quantidade de sítios ativos disponíveis e com o passar do tempo o contaminante que tem maior preferência vai tomando os sítios ativos disponíveis. Como o o-xileno é o contaminante mais competitivo e que apresenta maior capacidade de adsorção, ele vai sendo adsorvido em maior quantidade. A partir de $6 \mathrm{~h}$ de adsorção dos três contaminantes, observa-se um efeito competitivo entre o benzeno e o tolueno que começam a disputar pelos sítios ativos disponíveis do adsorvente. Como o o-xileno é o mais competitivo, ele vai deslocando os demais compostos. A partir das $6 \mathrm{~h}$ de adsorção, o tolueno que vinha adsorvendo em maior quantidade que o benzeno após a saturação de ambos, vai sendo dessorvido e o benzeno começa a adsorver nos sítios ativos disponíveis. 


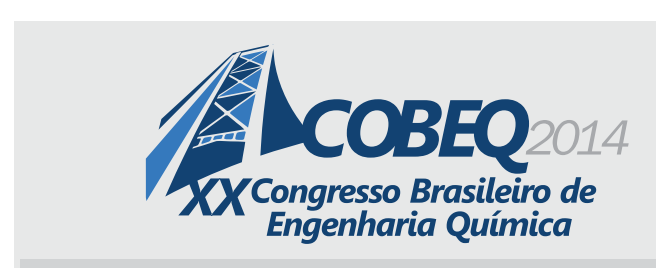

(a)

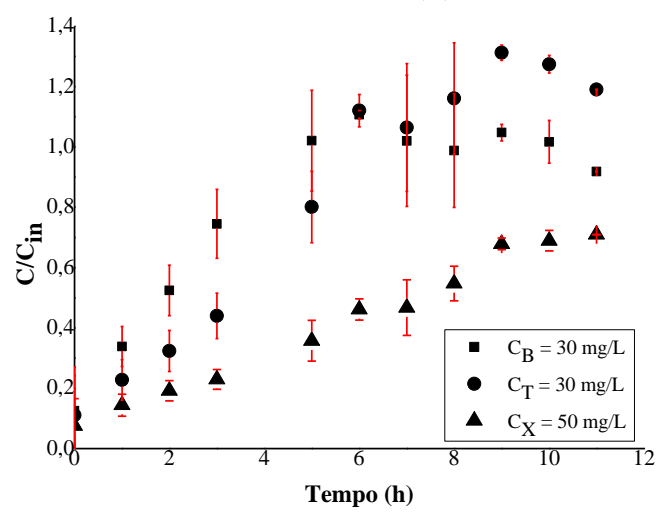

(c)

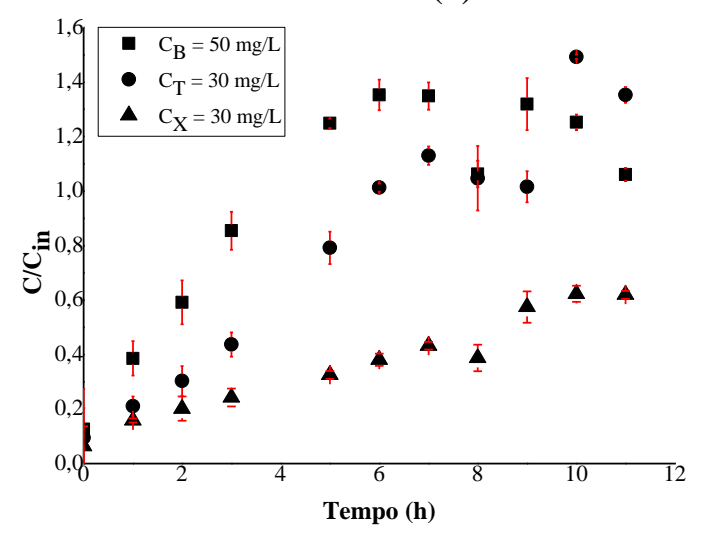

19 a 22 de outubro de 2014

Florianópolis/SC (b)

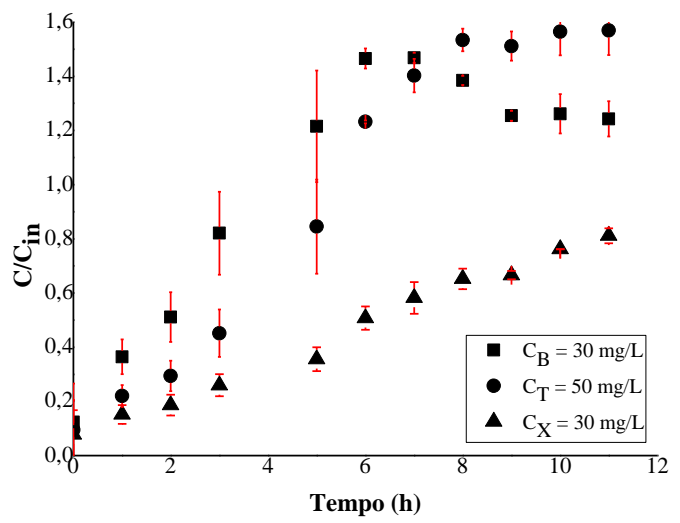

(d)

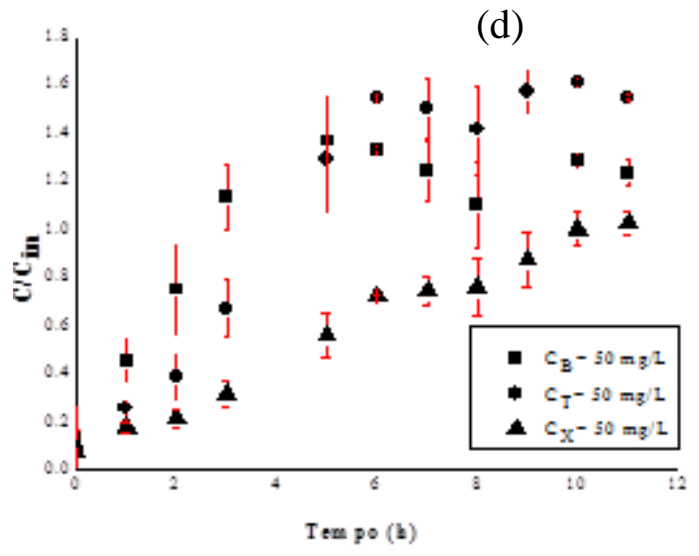

Figura 2 - Curvas de ruptura dos compostos BTX para as combinações: (a) Cin = (30B, 30T, 50X) mg/L); (b) Cin = (30B, 50T, $30 \mathrm{X}) \mathrm{mg} / \mathrm{L} ;(\mathrm{c}) \mathrm{Cin}=(50 \mathrm{~B}, 30 \mathrm{~T}, 30 \mathrm{X}) \mathrm{mg} / \mathrm{L} ; \mathrm{e}(\mathrm{d}) \mathrm{Cin}=(50 \mathrm{~B}, 50 \mathrm{~T}, 50 \mathrm{X}) \mathrm{mg} / \mathrm{L} ; \mathrm{L}=7 \mathrm{~cm} \mathrm{e} \mathrm{Q}=40 \mathrm{~mL} / \mathrm{min}$.

Através da Figura 2 (b), pode-se verificar o mesmo comportamento anterior, sendo que a mistura tricomponente apresenta as concentrações iniciais de 30,50, $30 \mathrm{mg} / \mathrm{L}$ de benzeno, tolueno e o-xileno, respectivamente. Observa-se que por mais que a concentração do tolueno seja a maior $(50 \mathrm{mg} / \mathrm{L})$ comparada ao benzeno $(30 \mathrm{mg} / \mathrm{L})$ e ao o-xileno $(30 \mathrm{mg} / \mathrm{L})$, o o-xileno ainda é contaminante que é mais adsorvido na superfície do adsorvente. Sabe-se que o tolueno apresenta maior concentração, porém o o-xileno é ainda o mais competitivo. Verifica-se que após $11 \mathrm{~h}$ de adsorção, a coluna não se encontra saturada com o-xileno ( $75 \%$ saturada), sendo que para o benzeno a coluna saturou em $4 \mathrm{~h}$ e para o tolueno em $5.5 \mathrm{~h}$, mesmo tempo comparado a uma concentração menor $(30 \mathrm{mg} / \mathrm{L})$. Nesta figura o mesmo efeito competitivo que o anterior pode ser observado entre o benzeno e o tolueno. Através da Figura 2 (c) também se observa o mesmo comportamento, mas agora a mistura tricomponente apresenta as concentrações iniciais 50, 30, $30 \mathrm{mg} / \mathrm{L}$ de benzeno, tolueno e o-xileno, respectivamente. Analisando a figura observa-se que mesmo que a concentração do benzeno seja a maior, $50 \mathrm{mg} / \mathrm{L}$, comparada ao tolueno $30 \mathrm{mg} / \mathrm{L} \mathrm{e}$ ao o-xileno $30 \mathrm{mg} / \mathrm{L}$, o o-xileno ainda é contaminante que é mais adsorvido pelo adsorvente. $\mathrm{O}$ benzeno é o contaminante que apresenta maior concentração e é o que apresenta menor afinidade com os sítios ativos do adsorvente. $\mathrm{O}$ benzeno começa a sair da coluna em um tempo menor, 3.5 $\mathrm{h}$, sendo que o tolueno satura a coluna em $6 \mathrm{~h}$, e em $11 \mathrm{~h}$ a coluna se encontra com $60 \%$ de 


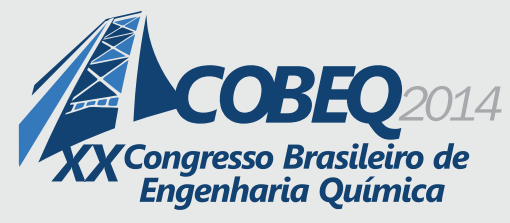

19 a 22 de outubro de 2014

Florianópolis/SC

saturação de o-xileno. Analisando-se a Figura 2 (d), que apresenta o resultado para a mistura tricomponente, na concentração inicial de $50 \mathrm{mg} / \mathrm{L}$ de cada contaminante, observa-se para o resultado das curvas de ruptura, o mesmo comportamento competitivo quando comparado as curvas apresentadas para as demais concentrações anteriores, sendo que o o-xileno é o contaminante mais adsorvido na superfície do adsorvente. Verifica-se que após $11 \mathrm{~h}$ de adsorção a coluna se encontra saturada com o-xileno, sendo que para o benzeno a coluna satura em $2.5 \mathrm{~h}$ e para o tolueno em $4 \mathrm{~h}$. Os valores encontrados para a difusividade efetiva foram de $9.30 \times 10^{-11}$ $\mathrm{cm}^{2} / \mathrm{s}, 9.70 \times 10^{-9} \mathrm{~cm}^{2} / \mathrm{s}$, e $9.50 \times 10^{-7} \mathrm{~cm}^{2} / \mathrm{s}$ para os BTX respectivamente, calculados numericamente utilizando-se o modelo de difusão homogênea de acordo com Luz (2013).

Verifica-se que a concentração adimensional do benzeno e tolueno excedem a uma unidade. Isso pode ser explicado pelo seguinte fato: No estágio inicial da adsorção multicomponentes, há uma grande quantidade de sítios ativos no adsorvente, e os componentes que adsorvem fracamente e fortemente, são adsorvidos aos sítios ativos livremente. Com o avanço do tempo, os componentes que adsorviam mais fracamente não adsorvem com facilidade, mas avançam com o fluido e tomam os sítios ativos antes na parte frontal do leito fixo. Assim os compostos fortemente adsorvidos tendem a adsorver no sítio ativo do composto fracamente adsorvido, e eles desalojarão os sítios que foram ocupados pelos compostos fracamente adsorvidos. Por este motivo, a concentração dos compostos fracamente adsorvidos passa da concentração adimensional [1]. Segundo Sulaymon e Ahamed (2008), uma provável explicação, está relacionado com o número de Biot. Neste caso foram encontrados os seguintes números de $\begin{array}{llllll}\text { Biot para } & \text { a } & \text { mistura } & \text { dos } & \text { compostos } & \text { BTX }\end{array}$ $\left[B i_{M B}=4.7499 \times 10^{8} ; B i_{M T}=4.5541 \times 10^{6} ; B i_{M X}=4.6499 \times 10^{4}\right]$.

\section{CONCLUSÃO}

Neste trabalho foi estudada a adsorção multicomponente dos compostos BTX utilizando-se como adsorvente carvão vegetal de casca de coco ativado termicamente. Foi verificada a competitividade entre os contaminantes pelo sítio ativo do adsorvente. À medida que o número de Biot aumenta para cada soluto, a taxa de adsorção competitiva irá diminuir e a forma das curvas de ruptura será plana e terá um menor "breakpoint". Isto é devido à baixa resistência intrapartícula e também devido à diminuição do tempo de contato para atingir a saturação. Um maior número de Biot pode ser observado para o benzeno e tolueno na mistura BTX, os quais são os contaminantes que apresentam menor difusividade intrapartícula comparados ao o-xileno. Estes resultados estão de acordo com os resultados observado por Sulaymon e Ahmed (2008), que estudaram a competitividade de adsorção de furfural e compostos fenólicos em leito fixo de carvão ativado. $\mathrm{O}$ carvão ativado em estudo apresentou uma grande área superficial e um vasto volume de poros, o que caracteriza o carvão ativado de casca de coco como um ótimo adsorvente para a adsorção dos compostos BTX.

\section{REFERÊNCIAS}

DAIFULlAH, A. A. M.; GIRGIS, B. S. Impact of Surface Characteristics of Activated Carbon on Adsorption of BTEX. Colloid. Surface., v. 214, p. 181-193, 2003. 
DEAN, B. J. Recent findings on the genetic toxicology of benzene, toluene, ethylbenzene, xylenes and phenols. Mutat. Res, v. 145, p. 153-181, 1985.

GUELLI U. DE SOUZA, S. M. A.; BRANDÃO, H. L.; ULSON DE SOUZA, A. A. Modeling of liquid pollutant biodegradation process in a fluidized bed reactor with biofilm. Separ. Purif. Techn., v. 60, p. 162-173, 2008.

HERNÁNDEZ, M. A.; CORONA, L.; GONZÁLEZ, A. I.; ROJAS, F.; LARA, V. H.; SILVA, F. Quantitative Study of the Adsorption of Aromatic Hydrocarbons (Benzene, Toluene, and pXylene) on Dealuminated Clinoptilolites. Ind. Eng. Chem. Res., v. 44, p. 2908-2916, 2005.

HU, X., QIAO, S., ZHAO, X.S. AND LU, G.Q., Adsorption Study of Benzene in Ink-Bottle-Like MCM-41. Ind. Eng. Chem. Res., v. 40, p. 862-867, 2001.

KHAN, A. R.; RIAZI, M. R.; AL-ROOMI, Y. A. A thermodynamic model for liquid adsorption isotherms. Separ. Purif. Techn., v. 18, p. 237-250, 2000.

KOUYOUMDJIEV, M. S. Kinetics of Adsorption from Liquid Phase on Activated Carbon, Thesis, University of Technology, 1992.

LIN, H.S. AND HUANG, C.Y., Adsorption of BTEX from Aqueous Solutions by Macroreticular Resins. J. Hazard. Mater., v. 70, p. 21-37, 1999.

LUZ, A. D., GUELli U. DE SOUZA, S. M. A., LUZ, C., REZENDE, R. V. P.; ULSON DE SOUZA, A. A., Multicomponent Adsorption and Desorption of BTX Compounds Using Coconut Shell Activated Carbon: Experiments, Mathematical Modeling, and Numerical Simulation. Ind. Eng. Chem. Res., v. 52, p. 7896-7911, 2013.

MINISTÉRIO DA SAÚDE, 2000. Portaria No. 1469, de 29.12.2000. RIO + 20 United Nations Conference on Sustainable Development: The future we want, 20 - 22 de Junho de 2012, Rio de Janeiro - Brasil, Updated online: Junho 2013. http://www.uncsd2012.org/thefuturewewant.html

MURATA, M.; TSUJIKAWA, M.; KAWANISHI, S. Oxidative DNA damage by minor metabolites of toluene may lead to carcinogenesis and reproductive dysfunction, Biochem. Biophys. Res. Commun., v. 261, p. 478-483, 1999.

SULAYMON, A. H.; AHMED, K. W. Competitive adsorption of fulfural and phenolic compounds onto activated carbon in fixed bed column. Environ. Sci. Technol., v. 42, p. 392-397, 2008.

WIBOWO, N.; SETYADHI, L.; WIBOWO, D.; SETIAWAN, J.; ISMADJI, S. Adsorption of benzene and toluene from aqueous solutions onto activated carbon and its acid and heat treated forms: Influence of surface chemistry on adsorption. J. Hazard. Mater., v. 146, p. 237-242, 2007. 